\title{
Research
}

Paper

\section{Influence of DL $\alpha$-lipoic acid and vitamin-E against doxorubicin-induced biochemical and histological changes in the cardiac tissue of rats}

\author{
S.A. Ayaz, U. Bhandari, K.K. Pillai
}

Department of Pharmacology,

Faculty of Pharmacy, Jamia Hamdard (Hamdard

University)

New Delhi-110062, India

Received: 4.5.2004

Revised: 3.9 .2004

Accepted: 2.10.2004

Correspondence to:

K.K. Pillai

E-mail:

kkp20101950@rediffmail.com

\begin{abstract}
Objective: The present study was undertaken to find out the preventive and curative role of lipoic acid (LA) and vitamin E (Vit. E) on doxorubicin (DOX)-induced oxidative stress and to make comparative evaluation between LA and vitamin $\mathrm{E}$ in this regard.

Materials and Methods: Wistar albino rats were used in this experiment. DOX was administered intraperitoneally in six equal injections (each containing $2.5 \mathrm{mg} / \mathrm{kg}$ DOX at $48 \mathrm{~h}$ interval) to a total cumulative dose of $15 \mathrm{mg} / \mathrm{kg}$ over a period of 2 weeks to produce cardiotoxicity. Lipoic acid and vitamin E were administered as pretreatment and posttreatment. The biochemical parameters such as tissue glutathione (GSH), malondialdehyde (MDA), lactate dehydrogenase (LDH), catalase (CAT), superoxide dismutase (SOD), glutathione peroxidase (GPx), glutathione reductase (GR), glutathione-s-transferase (GST), and glucose-6-phosphate dehydrogenase (G6PD) were monitored after 30 days.

Results: Post-treatment with lipoic acid and vitamin E significantly protected the myocardium from the toxic effects of DOX, by reducing the levels of antioxidant enzymes such as CAT, SOD, GPx, GST, and G6PD towards normal and decreased the increased levels of malondialdehyde. It has also reduced the severity of cellular damage of the myocardium. The restoration of the endogenous antioxidant system clearly depicts that lipoic acid and vitamin $\mathrm{E}$ have produced their protective effect by scavenging the reactive oxygen species (ROS). Pretreatment with LA did not alter DOX-induced changes of histopathological parameters. Pretreatment with vitamin E has significantly increased the levels of blood and tissue GSH and significantly decreased the levels of MDA as compared to DOX-treated group. Vitamin E has significantly reduced the activities of the antioxidant enzymes except GSHR as compared to the DOX-treated group.

Conclusion: The study strongly supports the use of these antioxidants in the treatment of DOX-induced cardiotoxicity; however, vitamin E is better for both preventive and curative therapy but LA can be used only for curative therapy.
\end{abstract}

KEY WORDS: Antioxidants, cardiotoxicity, doxorubicin, free radicals.

\section{Introduction}

Doxorubicin (DOX) is a clinically well-established anticancer drug used for the treatment of solid tumors and hematologic malignancies. However, the development of a dose-dependent cardiotoxicity, which ultimately leads to cardiomyopathy with congestive heart failure ${ }^{[1]}$ has limited the use of this drug. Several mechanisms for the DOX-induced cardiotoxicity have been proposed, including membrane lipid peroxidation (LPO), free radical formation, ${ }^{[2]}$ mitochondrial damage ${ }^{[3]}$ and iron-dependent oxidative damage to macromolecules. ${ }^{[4]}$ Oxygen radicals are apparently involved in all of the mechanisms proposed.
In relation to oxidative stress, a study has put forward the evidence that the DOX-induced toxicity may ensue through free radical formation and subsequent redox cycle with oxygen, resulting in generation of reactive oxygen species (ROS) such as superoxide anion and hydrogen peroxide $\left(\mathrm{H}_{2} \mathrm{O}_{2}\right)$. In the presence of $\mathrm{Fe}^{2+}, \mathrm{H}_{2} \mathrm{O}_{2}$ is further reduced to the extremely reactive hydroxyl radical. ${ }^{[5]}$ These species may attack soluble cell components as well as membranes, eventually leading to impairment of cell functioning and cytolysis. ${ }^{[6]}$ The tissues with less developed antioxidant defence mechanism such as the heart is highly susceptible to injury by anthracycline-induced oxygen radicals. 
Alpha lipoic acid (LA) is a naturally occurring compound that was shown to be synthesized by animals and humans. It is used as a dietary supplement on the basis of its antioxidant properties. Lipoamide dehydrogenase, found only in the mitochondria, reduces free lipoic acid to dihydrolipoic acid (DHLA), which is a potent antioxidant. DL $\alpha$-lipoic acid and its reduced form dihydrolipoic acid, have been referred to as universal antioxidants that function in both aqueous and membrane phases. ${ }^{|7|}$ In recent years, it has been observed that there is a growing interest in the usage of these natural antioxidants as a protective strategy against the cardiovascular-related problems in experiments, such as ischemia-reperfusion ${ }^{[8]}$ and doxorubicin-induced cardiotoxicity. ${ }^{[9]}$ These conditions are produced as a result of generation of reactive oxygen species (ROS) and subsequent lipid peroxidation. Recently, one study has reported the potent antioxidant role of lipoic acid against the adriamycin-induced cardiotoxicity with $35 \mathrm{mg} / \mathrm{kg}$ dose of lipoic acid. ${ }^{[9]}$ DHLA (0.5 mM) accelerated iron-dependent hydroxyl radical generation and lipid peroxidation in liposomes, probably by reducing $\mathrm{Fe}^{3+}$ to $\mathrm{Fe}^{2+[10]}$ and the other report suggests that the prooxidant effects of LA and DHLA warrants further investigation. ${ }^{[11]}$ Vitamin $\mathrm{E}$ is reported to possess antioxidant property. Vitamin-E treated rats have shown approximately $50 \%$ decrease in mortality and infarct size owing to coronary occlusion as compared to the control group and also significantly attenuates the arrhythmic changes. ${ }^{[12]}$ Also, it has been reported that vitamin $\mathrm{E}$ acts as peroxyl radical trapping chain breaking antioxidant along with free radical scavenging property. $^{[13]}$

The purpose of this present study is to find out the role of lipoic acid and vitamin $\mathrm{E}$ as a reference standard and to compare their effects using the biochemical and histological parameters against the doxorubicin-induced cardiomyopathy in rats.

\section{Materials and Methods}

\section{Chemicals}

Doxorubicin was a generous gift from Dabur Research Laboratories (Ghaziabad, India). Lipoic acid was purchased from SRL laboratory (Mumbai, India). Vitamin E was purchased from E-Merck (Mumbai, India) and the LDH kit was purchased from Reckon Diagnostic Pvt. Ltd. (Baroda, India). All other chemicals and solvents used were of highest purity and analytical grade.

\section{Animals}

Adult Wistar rats of either sex (weighing 150-200 g), bred in the central animal house of the Hamdard University (New Delhi, India) were used. The animals were housed under standard light/dark cycles with free access to food (Amrut Laboratory Rat feed, Navmaharashtra Chakan Oil Mills Ltd., Pune, India) and water. Experiments on animals were conducted after obtaining approval from Hamdard University Animal Ethics Committee.

\section{Experimental protocols}

After acclimatization, the animals were randomly divided into eight groups, each group comprising of 10 animals. Five animals from each group were used for biochemical estimations and the remaining rats were used for the histopathological studies. The animals were allowed free ac- cess to food and water.

Group I animals served as normal control and received lactose $75 \mathrm{mg} / \mathrm{kg}$ in saline intraperitoneally (i.p.) in the same regimen as doxorubicin. Group II animals received doxorubicin alone $(2.5 \mathrm{mg} / \mathrm{kg}$, body weight in normal saline (i.p.) in six equal injections for a period of 2 weeks for a total cumulative dose of $15 \mathrm{mg} / \mathrm{kg}$, body weight). Group III animals received lipoic acid $20 \mathrm{mg} / \mathrm{kg}$, per oral (p.o.) for 15 days as a pretreatment followed by doxorubicin administration (dosage and duration were as in Group II). Group IV animals received doxorubicin (dosage and duration were as in Group II) and after 15 days lipoic acid $20 \mathrm{mg} / \mathrm{kg}$, p.o. for 15 days. Group V animals received only lipoic acid $20 \mathrm{mg} / \mathrm{kg}$, p.o. for 15 days. Group VI animals received vitamin E $50 \mathrm{IU} / \mathrm{kg}$, p.o. for 15 days followed by doxorubicin (dosage and duration were as in Group II). Group VII animals received doxorubicin (dosage and duration were as in Group II) and after 15 days vitamin E was administered $50 \mathrm{IU} / \mathrm{kg}$, p.o. for 15 days. Group VIII animals received only vitamin E $50 \mathrm{IU} / \mathrm{kg}$, p.o. for 15 days.

Control, as well as treated animals were observed for a period of 4 weeks, and their body weights were checked. At the end of the fourth week, the animals were killed under ether anesthesia and a midline abdominal incision was performed and the hearts tissue were quickly dissected out, washed in ice-cold saline, dried on a filter paper, and weighed. For histopathological studies, heart tissues of each group were stored in $10 \%$ formalin in saline before processing.

A portion of each heart was taken from all the groups and a $10 \% \mathrm{w} / \mathrm{v}$ homogenate was prepared in $0.9 \%$ buffered potassium chloride (pH 7.4) for the estimation of glutathione ${ }^{[14]}$ and malondialdehyde. ${ }^{[15]}$

The remaining portion of the heart tissue was used for the assay of cardiac damage marker enzyme and antioxidant enzymes. A $10 \% \mathrm{w} / \mathrm{v}$ homogenate was prepared in $0.05 \mathrm{M}$ phosphate buffer (pH 7.4). The homogenate was subjected to cold centrifugation at $4{ }^{\circ} \mathrm{C}$ for $20 \mathrm{~min}$ and used for estimation of lactate dehydrogenase, ${ }^{[16]}$ catalase, ${ }^{[17]}$ superoxide dismutase, ${ }^{[18]}$ glutathione peroxidase, ${ }^{[19]}$ glutathione reductase, ${ }^{[20]}$ glutathione-S-transferase, ${ }^{[21]}$ glucose-6-phosphate dehydro-genase, ${ }^{\mid 22]}$ and protein content. ${ }^{[23]}$

\section{Histopathological studies}

The hearts were fixed in $10 \%$ formalin. The specimens were processed by standard procedure and embedded in paraffinwax. The blocks were sectioned from the ventricular portion and 5-micron thick sections were stained according to the hematoxylin and eosin (H \& E) method given by Smith and Burton. ${ }^{[24]}$ The sections were examined by light microscopy.

\section{Statistical analysis}

Data were expressed as the mean \pm SEM. For a statistical analysis of the data, group means were compared by one-way analysis of variance (ANOVA) followed by Dunnett's test, which was used to identify differences between groups. $\mathrm{P}<0.05$ was considered significant.

\section{Results}

\section{Effect of lipoic acid pretreatment}

The chronic treatment with doxorubicin significantly decreased the total GSH levels in the cardiac tissue of wistar rats as compared to control group $(\mathrm{P}<0.01)$, lipoic acid 
pretreatment reduced the depletion of GSH in doxorubicintreated group. The levels of MDA, LDH, CAT, SOD, GPx, GR, GST, and G6PD were increased in the cardiac tissue of DOX group as compared to control group $(\mathrm{P}<0.01)$ and lipoic acid pretreatment significantly decreased the levels of these markers (Table 1, 2 and 3).

Effect of lipoic acid post-treatment

Curative treatment with lipoic acid could not increase the levels of total GSH as compared to DOX-treated group, but a significant reduction in the levels of MDA $(\mathrm{P}<0.01)$ as compared to DOX-treated animals was seen. Also, lipoic acid has not reduced the increased LDH activity. Lipoic acid has significantly reduced the activities of antioxidant enzymes $(\mathrm{P}<0.01)$ except GR (Tables 1, 2 and 3).

\section{Effect of vitamin E pretreatment}

Treatment with vitamin $\mathrm{E}$ has significantly increased $(\mathrm{P}$ $<0.01)$ the levels of GSH and significantly decreased the levels of MDA ( $\mathrm{P}<0.01)$ as compared to DOX-treated group and a significant change was found in the LDH activity $(\mathrm{P}<0.05)$ as compared to DOX group (Table 1). Vitamin E has significantly reduced the activities of the antioxidant enzymes ( $P$ $<0.01$ ) except GR as compared to the DOX-treated group (Tables 1, 2 and 3).

\section{Effect of vitamin $E$ post-treatment}

The post-treatment with vitamin E has not increased the GSH levels but it has significantly decreased the MDA levels $(\mathrm{P}<0.01)$ as compared to DOX-treated group (Table 1). Also, it has not reduced the LDH activity as compared to DOX-treated

\section{Table 1}

Effect of lipoic acid and Vit E on doxorubicin induced changes in glutathione, malondialdehyde and lactate dehydrogenase in heart tissue of rats

\begin{tabular}{|c|c|c|c|c|}
\hline Group & Drug treatment & $\begin{array}{l}\text { Glutathione } \\
\text { mmol/g heart }\end{array}$ & $\begin{array}{l}\text { Malondialdehyde } \\
\text { nmol/g heart }\end{array}$ & $\begin{array}{l}\text { Lactate dehydrogenase } \\
I U / L \text { of } 10 \% \mathrm{w} / \mathrm{v} \text { heart homogenate }\end{array}$ \\
\hline I & Lactose $(0.1 \%$ in saline $)$ & $19.99 \pm 3.09$ & $41.23 \pm 5.03$ & $17.68 \pm 1.34$ \\
\hline II & DOX & $4.55 \pm 0.63^{* *}$ & $261.39 \pm 16.44 * *$ & $46.31 \pm 13.88^{\star *}$ \\
\hline III & DOX Pretreated with LA & $16.19 \pm 0.39 \#$ & $206.05 \pm 14.35^{\#}$ & $22.03 \pm 3.99^{\#}$ \\
\hline IV & DOX Post-treated with LA & $9.43 \pm 0.71$ & $181.39 \pm 25.02^{\# \#}$ & $36.19 \pm 1.17$ \\
\hline V & LA & $13.57 \pm 2.37$ & $65.55 \pm 6.97^{*}$ & $22.76 \pm 3.34$ \\
\hline VI & DOX Pretreated with Vit.E & $17.90 \pm 2.77 \#$ & $76.49 \pm 4.64^{\# \#}$ & $23.0 \pm 4.32^{\#}$ \\
\hline VII & DOX Post-treated with Vit. E & $8.58 \pm 1.58$ & $99.40 \pm 6.90^{\# \#}$ & $27.27 \pm 4.02$ \\
\hline VIII & Vit. E & $15.97 \pm 0.71$ & $73.06 \pm 1.36^{*}$ & $20.04 \pm 3.35$ \\
\hline One-way & $\mathrm{F}$ & 8.25 & 40.83 & 2.76 \\
\hline ANOVA & df & 7,32 & 7,32 & 7,32 \\
\hline
\end{tabular}

Values are mean $\pm S E M ; n=5$ in each group. ${ }^{*} P<0.05$ when compared to Group I; ${ }^{* *} P<0.01$ when compared to Group I; \# $P<0.05$ when compared to Group II; \#\# $<0.01$ when compared to Group II. DOX: Doxorubicin was given in a dose of $2.5 \mathrm{mg} / \mathrm{kg}$, i.p in six equal doses on alternate days for two weeks. LA: Lipoic acid was administered $20 \mathrm{mg} /$ $\mathrm{kg}$ p.o for 15 days. Vit. E: Vit $\mathrm{E}$ was administered $50 \mathrm{IU} / \mathrm{kg}$ p.o for 15 days.

\section{Table 2}

Effect of lipoic acid and Vit E on doxorubicin induced changes in catalase, superoxide dismutase and glutathione peroxidase activity in heart tissue of rats

\begin{tabular}{|c|c|c|c|c|}
\hline Group & Drug treatment & Catalase (CAT) & $\begin{array}{c}\text { Superoxide } \\
\text { dismutase (SOD) }\end{array}$ & $\begin{array}{c}\text { Glutathione } \\
\text { peroxidase (GPX) }\end{array}$ \\
\hline I & Lactose $(0.1 \%$ in saline $)$ & $32.99 \pm 4.05$ & $86.62 \pm 2.28$ & $49.89 \pm 2.20$ \\
\hline II & DOX & $126.17 \pm 5.82^{* *}$ & $160.95 \pm 7.25^{\star \star}$ & $179.59 \pm 7.03^{* *}$ \\
\hline III & DOX Pretreated with LA & 170.02+20.19@ & $108.66 \pm 7.29^{\# \#}$ & $49.07 \pm 17.55^{\# \#}$ \\
\hline IV & DOX Post-treated with LA & $72.05 \pm 9.05^{\# \#}$ & $27.94 \pm 7.82^{\# \#}$ & $85.83 \pm 20.51^{\# \#}$ \\
\hline $\mathrm{V}$ & LA & $16.59 \pm 3.46^{\star *}$ & $7.72 \pm 3.10^{\star *}$ & $70.74 \pm 11.42^{*}$ \\
\hline VI & DOX Pretreated with Vit.E & $61.07 \pm 4.81^{\# \#}$ & $84.14 \pm 2.79^{\# \#}$ & $47.44 \pm 3.42^{\# \#}$ \\
\hline VII & DOX Post-treated with Vit.E & $69.11 \pm 8.41^{\# \#}$ & $23.50 \pm 5.55^{\# \#}$ & $88.73 \pm 19.87^{\# \#}$ \\
\hline VIII & Vit. E & $18.55 \pm 1.49^{*}$ & $8.74 \pm 2.22^{\star *}$ & $48.28 \pm 8.61$ \\
\hline One-way & $F$ & 33.90 & 108.77 & 11.46 \\
\hline ANOVA & $d f$ & 7,32 & 7,32 & 7,32 \\
\hline
\end{tabular}

Values are mean $\pm S E M ; n=5$ in each group. ${ }^{*} P<0.05$ when compared to Group I; ${ }^{* \star} P<0.01$ when compared to Group I; @ $P<0.05$ when compared to Group II; \#\# $P<0.01$ when compared to Group II. DOX: Doxorubicin was given in a dose of $2.5 \mathrm{mg} / \mathrm{kg}$, i.p in six equal doses on alternate days for two weeks. LA: Lipoic acid was administered $20 \mathrm{mg} /$ $\mathrm{kg}$, p.o for 15 days. Vit. E: Vit E was administered $50 \mathrm{IU} / \mathrm{kg}$, p.o for 15 days. CAT, nmol of $\mathrm{H}_{2} \mathrm{O}_{2}$ consumed per min per mg protein; GPx, nmol of NADPH oxidized per min per mg protein; SOD, amount of enzyme required to give $50 \%$ inhibition of pyrogallol autooxidation, $U$ per $\mathrm{mg}$ protein. 


\section{Table 3}

Effect of lipoic acid and Vit E on doxorubicin induced changes in glutathione reductase, glutathione-s-transferase and glucose-6phosphate dehydrogenase activity in heart of rats

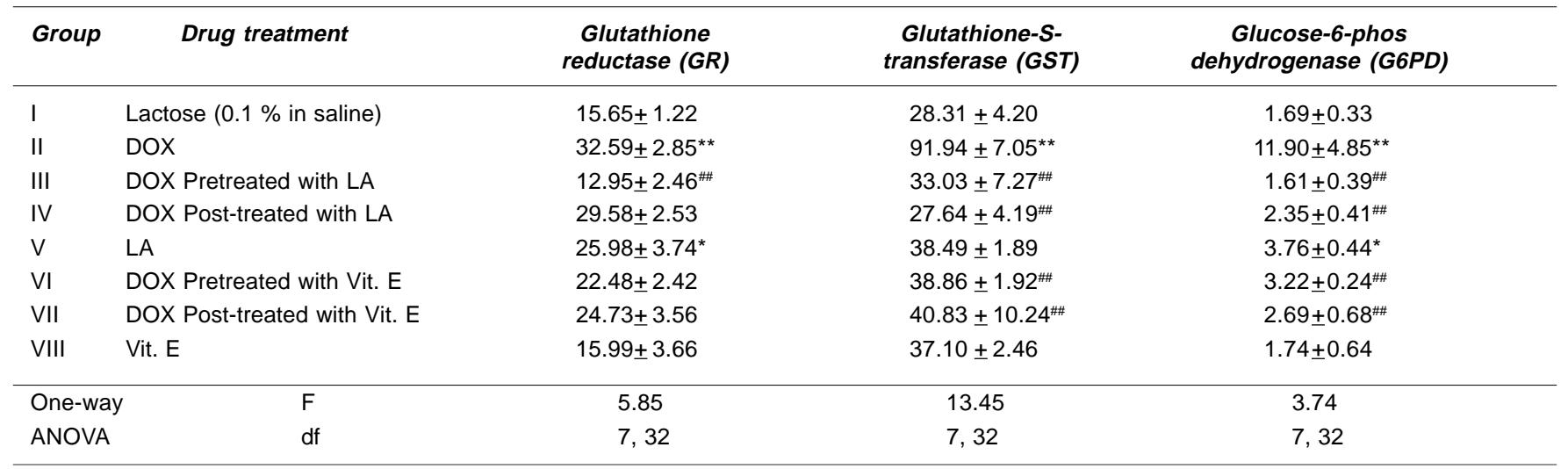

Values are mean $\pm S E M ; n=5$ in each group. ${ }^{*} \mathrm{P}<0.05,{ }^{*} \mathrm{P}<0.01$ when compared to Group I; \#\# $\mathrm{P}<0.01$ when compared to Group II. DOX: Doxorubicin was given in a dose of $2.5 \mathrm{mg} / \mathrm{kg}$, i.p in six equal doses on alternate days for two weeks. LA: Lipoic acid was administered $20 \mathrm{mg} / \mathrm{kg}, \mathrm{p} .0$ for $15 \mathrm{days}$. Vit. E-Vit E was administered $50 \mathrm{IU} / \mathrm{kg}, \mathrm{p} .0$ for 15 days. GR-nmol of NADPH oxidized per min per mg protein; GST-nmol of 1-chloro 2,4 dinitrobenzene (CDNB) conjugate formed per min per mg protein; G6PD-nmol of reduced NADP oxidized per min per mg protein.

animals (Table 1).

Vitamin E has significantly decreased the levels of the antioxidant enzymes $(\mathrm{P}<0.01)$ except GR as compared to the DOXtreated group (Table 2 and 3 ).

Histopathological findings

The vehicle treated rat, that is, Group I did not show any morphological changes and heart showed normal appearance. The cardiac muscle fibres were found to be of uniform size, shape, and configurations with no vacuolated cells were seen. There was no necrosis and no inflammatory cell infiltrates were present (Figure 1). DOX produced a massive change in the myocardium showing a varying degree of vacuolar changes in the cardiac muscle fibres. The vacuolated cells were found to be more towards the endocardial surface of the heart. In addition, necrosis of cardiac muscle fibres with isolated cells showing features of hypertrophy in between the necrotic and fragmented muscle fibres was seen (Figure 2). Treatment with lipoic acid before DOX challenge showed an extensive vacuolation with a lacy appearance in the myocardial fibres near atrial endocardium (Figure 3) and the post-treatment with lipoic acid has shown lessened morphological changes where only patchy vacuolation restricted to subendocardial layers was observed (Figure 4). Post-treatment with vitamin E also showed a protection with less morphological changes such as patchy and scattered vacuolation restricted to subendocardial layers was observed (Figure 5).

\section{Discussion}

DOX-induced cardiotoxicity and its prevention by antioxidants and iron-chelators have been found to be of limited success. ${ }^{[25-27]}$ Some studies have reported the pro-oxidant property of lipoic acid where the reduced form of lipoic acid, that is, dihydrolipoic acid accelerated iron-dependent hydroxyl radical generation and lipid peroxidation in liposomes probably by reducing $\mathrm{Fe}^{3+}$ to $\mathrm{Fe}^{2+}{ }^{[10]}$ and the other report suggests that pro-oxidant effect of lipoic acid and dihydrolipoic acid needs
Figure 1. Photomicrograph of vehicle treated Group I heart showing normal myocardial fibres ( $\mathrm{H} \& \mathrm{E} 400 \mathrm{X})$

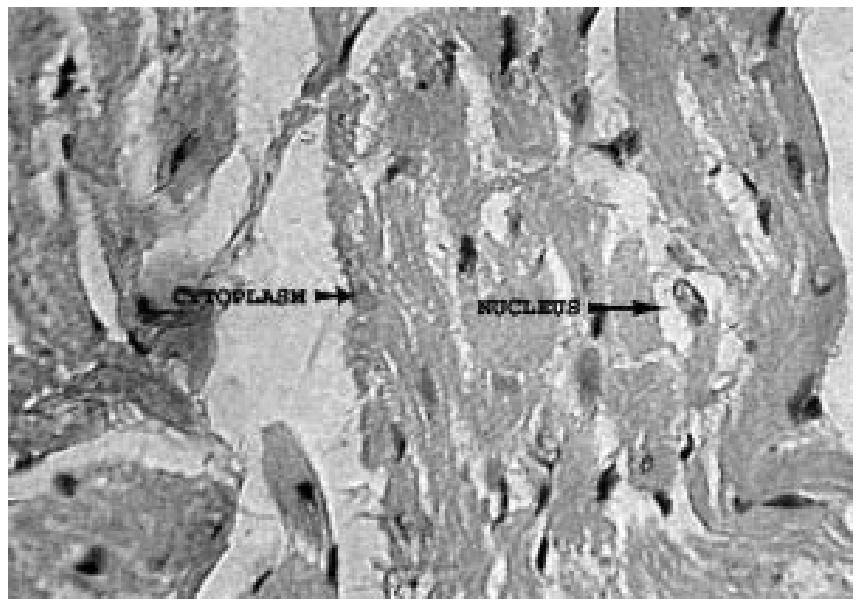

Figure 2. Photomicrograph of doxorubicin-treated Group II showing (arrows) patchy necrosis and a single vacuolated hypertrophied myocardial fibre ( $H$ \& E 400X)

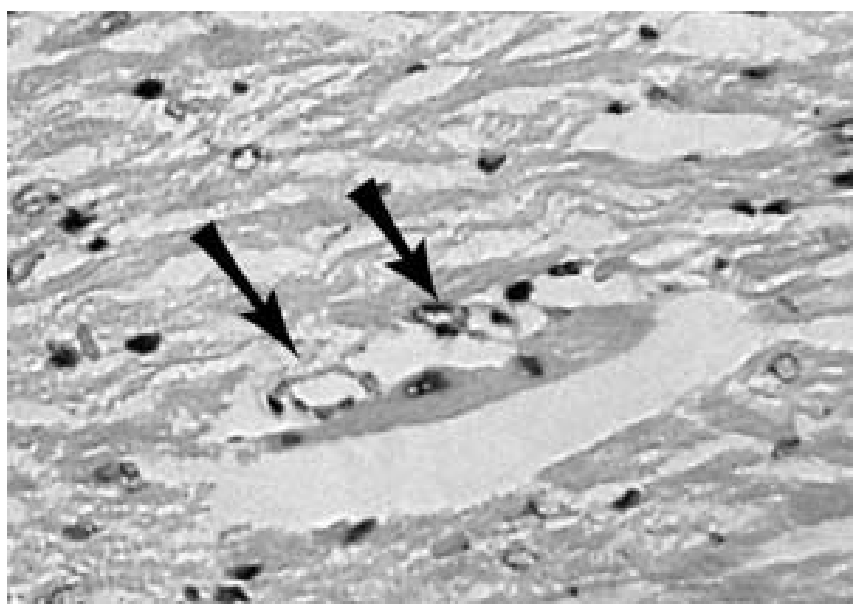


Figure 3. Photomicrograph of Group III pretreated with lipoic acid showing extensive vacuolation of cardiac muscle fibres (Vacuoles marked by 'V') (H \& E 400X)

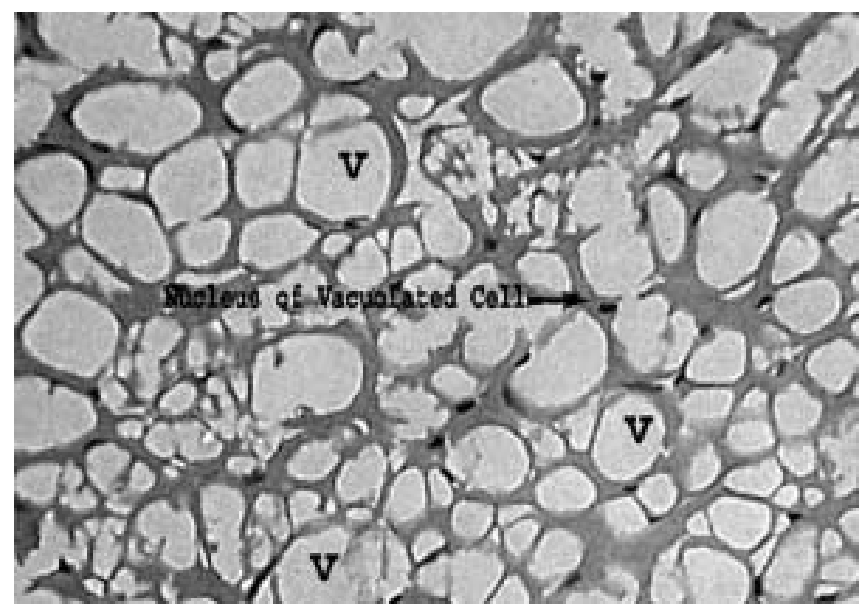

Figure 4. Photomicrograph of Group IV post-treated with lipoic acid showing vacuolated cells (arrow) (H \& E 400X)

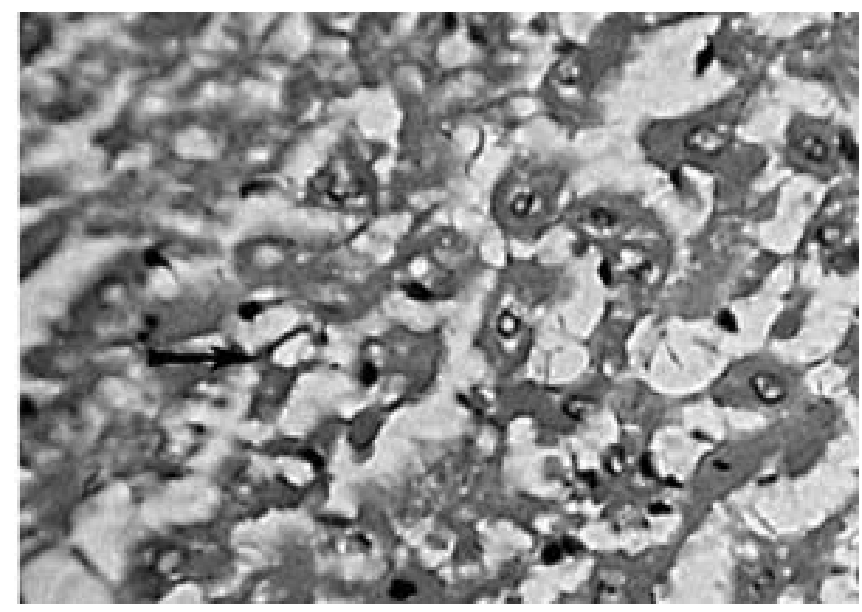

Figure 5. Photomicrograph of Group VII post-treated with vitamin $\mathrm{E}$ showing vacuolated cells (arrows) (H \& E 400X)

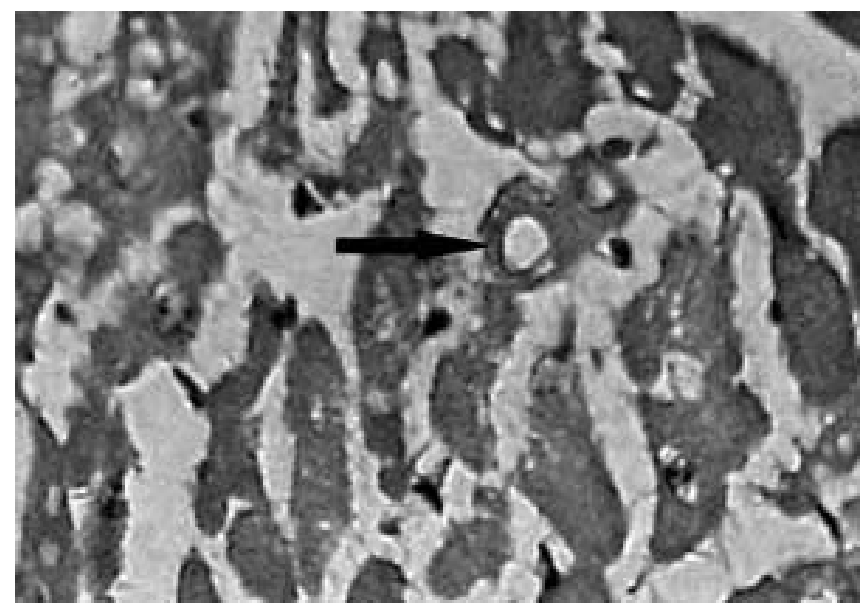

further investigation. ${ }^{[11]}$ Therefore, the present study was undertaken to find out the role of lipoic acid and vitamin $\mathrm{E}$ as reference standard in DOX-induced cardiotoxicity.
The chronic administration of DOX showed significant decrease in the levels of reduced glutathione and a significant increase in the levels of MDA and LDH activity in heart homogenate. It has been shown that marked decrease in GSH pool occurs in many tissues after acute and chronic DOX toxicities ${ }^{[28-30]}$ and an elevated level of MDA was shown in the rat heart tissue with DOX. DHLA is known to reduce glutathione disulfide (GSSG) to GSH and lipoic acid could have either mitigated the GSH consumption by acting as an alternate ROS scavenger or increase GSH levels by stimulating its biosynthesis by an unknown mechanism, also the increased intracellular GSH levels may activate the glutathione related enzymes, this may be a possible mechanism by which lipoic acid has restored the GSH levels in the heart tissue. The present study results in a decrease in lipid peroxidation product, that is, malondialdehyde with lipoic acid treatment and the results are in agreement with studies where lipoic acid has reduced the lipid peroxidation in DOX toxicity. ${ }^{[9,31]}$ The rapid cell swelling of sub-sarcolemmal bulbs and injured myocardium could facilitate the loss of intracellular enzymes in DOX-treated rats, this might be the possible mechanism for the increased levels of $\mathrm{LDH}$ in serum. ${ }^{\left[{ }^{3}{ }^{32]}\right.}$ Our results confirm the excess activity of $\mathrm{LDH}$ in cardiac tissue. This might also be due to induction or activation of LDH in cardiac tissue following DOX treatment. Similar observation was reported by Deepa $e t$ al. ${ }^{[33]}$ The pretreatment with lipoic acid and vitamin E significantly reduced the activity of LDH. Thus, the role of lipoic acid and vitamin E on LDH activity in myocardium needs further investigation. In two studies on DOX-induced cardiotoxicity lipoic acid has shown the protective effect and restored the leakage of cytosolic enzyme LDH from the myocardial cells ${ }^{[9,31]}$ and thereby maintained the cell integrity.

Many investigators have reported the protective and antioxidant role of lipoic acid against the animal models in which the pathogenesis was produced by oxidative stress. Abdul Hakeem et al. and Balachander et al. reported the protective antioxidant role of lipoic acid in DOX-induced toxicity. ${ }^{[9,31]}$ Also Geetha et al. and Milei et al. have reported the antioxidant potential of vitamin E in DOX-induced toxicity. ${ }^{[29,34]}$

Lipoic acid and vitamin E treatment caused a significant restoration of the antioxidant enzymes such as CAT, SOD, GPX, GST, and G6PD, where the activities of these enzymes were increased in the heart tissue of DOX-treated group as compared to vehicle-treated group. The increase in the activities of all these enzymes in the heart tissue might be owing to a compensatory mechanism and an effort made by the myocardium to detoxify the oxygen radicals. Lipoic acid and vitamin E have significantly restored the levels of the above enzymes towards normal, indicating the beneficial antioxidant potential of lipoic acid and vitamin E in DOX-induced cardiotoxicity.

In the present study, the biochemical changes support the histopathological changes, where DOX in chronic administration has produced its characteristic morphological changes in the myocardium. The myocardial morphological changes observed in DOX-treated rats were similar to those previously reported. ${ }^{[29,35]}$ During the preventive treatment, massive vacuolation of myocardium near the atrial endocardium might be due to endogenous conversion of lipoic acid to dihydrolipoic 
acid (DHLA). However, one study has reported that DHLA acts as a pro-oxidant in an in vitro condition, where it accelerates the iron-dependent hydroxyl radical generation and lipid peroxidation, probably by reducing $\mathrm{Fe}^{3+}$ to $\mathrm{Fe}^{2+} .{ }^{101} \mathrm{Lipoic}$ acid is an antioxidant and antioxidants also exhibit antiangiogenic effect and hence may be harmful in normal animals and might be beneficial in animals under oxidative stress. Thus, antioxidants act as double-edged weapons. Reduction in the severity of DOX-induced histological changes reveals that curative treatment with lipoic acid has beneficial effect. The administration of vitamin E to the DOX-treated rats also showed the protective effect on the myocardium with a significant decrease in the extent and severity of myocardial damage. The protective changes offered by vitamin $\mathrm{E}$ might be due to its antioxidant potential, where it is known that vitamin $\mathrm{E}$ acts as peroxyl radical trapping chain-breaking antioxidant along with free radical scavenging property. ${ }^{[13]}$

In conclusion, the cardiotoxicity induced by DOX is in relation with oxidative stress. Our study suggests that lipoic acid could be used as an antioxidant during curative therapy rather than preventive therapy. On the contrary, vitamin E could be used as an antioxidant both in prevention and curative therapy. Thus, our study reveals that vitamin $\mathrm{E}$ is an ideal agent for doxorubicin-induced cardiotoxicity as compared to lipoic acid.

\section{Acknowledgments}

This study is supported by University Grants Commission (UGC) New Delhi, India. We thank Mr. Siraj Hussian, Vice Chancellor, Jamia Hamdard for providing the research facility. We are thankful to Mrs. Shaukat Shah, Incharge, Central Animal House Facility, Jamia Hamdard, for providing the animals. We thank Mr. Mushtaq Ahmad for assisting in the experimental work.

\section{References}

1. Lefrak EA, Pitha J, Rosenheim S, Gottlieb T. A clinicopathologic analysis of adriamycin cardiotoxicity. Cancer 1973;32:302-14.

2. Yin $\mathrm{X}, \mathrm{Wu} \mathrm{H}$, Chen $\mathrm{Y}$, Kang YJ. Induction of antioxidants by adriamycin in mouse heart. Biochem Pharmacol 1998;56:87-93.

3. Hershko C, Link G, Tzahor M, Pinson A. The role of iron and iron chelators in anthracycline cardiotoxicity. Leuk Lymphoma 1993;11:207-14.

4. Thomas CE, Aust SD. The release of iron from ferritin by cardiotoxic anthracycline antibiotic. Arch Biochem Biophys 1986;248:684-9.

5. Sinha BK, Politi PM. Antharcyclines. Cancer Chemother Biol Response Modif 1990;11:45-57.

6. Daoud SS. Cell membranes as targets for anticancer drug action. Anticancer Drugs 1992;3:443-53.

7. Kagan VE, Shvedova A, Serbinova E, Khan S, Swanson C, Powell R, et al. Dihydrolipoic acid a universal antioxidant both in the membrane and in the aqueous phase. Reduction of peroxyl, ascorbyl and chromanoxyl radicals. Biochem Pharmacol 1992;44:1637-49.

8. Thurich T, Bereiter-Hahn J, Schneider M, Zimmer G. Cardioprotective effects of dihydrolipoic acid and tocopherol in right heart hypertrophy during oxidative stress. Arzneimittelforschung 1998;48:13-21.

9. Balachandar AV, Malarkodi KP, Varalakshmi P. Protective role of DL $\alpha$-lipoic acid against-induced cardiac lipid peroxidation. Hum Exp Toxicol 2003;22:24954.

10. Scott BC, Aruoma OI, Evans PJ, O'Neill C, Vander Vliet A, Cross CE, et al. Lipoic acid and dihydrolipoic acid as antioxidants a critical evaluation. Free
Radic Res 1994;20:119-33.

11. Hadi M, Lester P, Nils-Erik LS. Antioxidant and prooxidant activities of $\alpha$-lipoic acid and dihydrolipoic acid. Toxicol Appl Pharmacol 2002;182:84-90.

12. Sethi R, Takeda N, Nagano M, Dhalla N S. Beneficial effects of vitamin E treatment in acute myocardial infarction. J Cardiovasc Pharmacol Ther 2000; 5:51-8.

13. Tappel Al. Measurement of and protection from in vivo lipid peroxidation. In: Prye WA, editor. Free radicals in Biology. New York: Academic Press; 1980. p. 1-47.

14. Ellman GL. Tissue sulfhydryl groups. Arch Biochem Biophys 1959; 82:70-7.

15. Ohkawa H, Ohish N, Yagi K. Assay for lipid peroxides in animal tissues by thiobarbituric acid. Anal Biochem 1979; 95:351-8.

16. Lum G, Gambino SR. A comparison of serum versus heparinised plasma for routine chemistry tests. Am J Clin Pathol 1974; 61:108-13.

17. Clairborne A. Catalase activity. In: Greenwald RA, editor. Handbook of methods for oxygen radical research. Boca Raton: CRC Press; 1985. p. 283-4.

18. Marklund SL. Pyrogallol autooxidation. In: Greenwald RA, editor. Handbook of methods for oxygen radical research. Boca Raton: CRC Press; 1985. p. 2437.

19. Paglia DE, Valentine WN. Studies on the quantitative and qualitative characterization of erythrocyte glutathione peroxidase. J Lab Clin Med 1967; 70:15869.

20. Carlberg I, Mannervik B. Purification and characterization of the flavoenzyme glutathione reductase from rat liver. J Biol Chem 1975;250:5475-80.

21. Habig WH, Pabst MJ, Jakoby WB. Glutathione S-transferase. The first enzymatic step in mercapturic acid formation. J Biol Chem. 1974; 249:7130-9.

22. Zaheer N, Tewari KK, Krishnan PS. Exposure and solubilisation of hepatic mitochondrial shunt dehydrogenases. Arch Biochem Biophys 1965;109:6468.

23. Lowry OH, Rosenbrough NT, Farr AL, Randall AT. Protein measurement with the folins phenol reagent. J Biol Chem 1951;193:265-75.

24. Smith A, Burton J. A color atlas of histological staining techniques. In: Smith A, Burton J, editors. London: Wolfe Medical Publications; 1977.

25. Myers C, Bonow R, Palmeri S, Jenkins J, Corden B, Locker G, et al. A randomized controlled trial assessing the prevention of doxorubicin cardiomyopathy by N-acetlycysteine. Semin Oncol 1993;10: 53-5.

26. Herman EH, Ferrans VJ. Influence of vitamin E and ICRF-187 on chronic doxorubicin cardiotoxicity in miniature swine. Lab Invest 1983; 49: 69-77.

27. Pritsos CA, Sokoloff M, Gustafson DL. PZ-51 (Ebselen) in vivo protection against adriamycin induced mouse cardiac and hepatic lipid peroxidation and toxicity. Biochem Pharmacol 1992;44:839-41.

28. Doroshow JH, Looker GY, Ifrim I, Myers CE. Prevention of doxorubicin cardiac toxicity in the mouse by N-acetylcysteine. J Clin Invest 1981;68:1053-64.

29. Geetha A, Sankar R, Thankmani M, Shyamala Devi CS. $\alpha$-Tocopherol reduces doxorubicin-induced toxicity in rats histological and biochemical evidence. Indian J Physiol Pharmacol 1990; 34:94-8.

30. Mohamed HE, El-Swefy SE, Hagar HH. The protective effect of glutathione administration on adriamycin induced acute cardiac toxicity in rats. Pharmacol Res 2000; 42:115-21.

31. Abdul Hakeem AAM, Gado A M, AL-Shabanah OA, Mansour M A. Alpha lipoic acid ameliorates myocardial toxicity induced by doxorubicin. Pharmacol Res 2000;46:499-503.

32. Monnet $\mathrm{E}$, Orton $\mathrm{C}$. A canine model of heart failure by intracoronary adriamycin injection; hemodynamic and energetic results. J Cardiac Fail 1999;5:255-64.

33. Deepa P R, Varalakshmi P. Protective effect of low molecular weight heparin on oxidative injury and cellular abnormalities in adriamycin-induced cardiac and hepatic toxicity. Chem Biol Interact 2003;146:201-10.

34. Milei J, Boveris A, Llesuy S, Molina HA, Storino R, Ortega D, et al. Amelioration of adriamycin induced cardiotoxicity in rabbits by prenylamine and vitamin A and E. Am Heart J 1986;111:95-102.

35. Van Vleet JF, Greenwood L, Ferrans VJ, Rebar AH. Effect of selenium and vitamin $E$ on adriamycin-induced cardiomyopathy in rabbits. Am J Vet Res 1978;39:997-1010. 